\title{
Sales Force Training Evaluation
}

Kim Tan, California State University San Bernardino, USA

Eric Newman, California State University San Bernardino, USA

\begin{abstract}
An important indicator of an effective sales force training program is the evaluation of whether or not the training has directly impacted professional selling in retail organizations as defined by sales volume, sales personnel performance as well as other bottom line metrics. Despite spending thousands of dollars training their sales force every year, retail organizations often fail to follow through in evaluating the effectiveness of their training programs, thereby not allowing corrective actions for improvements to take root. This article investigates the importance of sales training evaluations and provides insights into the challenges and impediments faced by retailers in conducting sales training evaluation. This study essentially propose utilizing Kirkpatrick's FourLevel Training Evaluation Model (Donald Kirkpatrick, 1994) to examine the interrelationships among its four levels of training evaluation (reaction, learning, behavior change, and organizational outcomes) and how they can be applied in determining sales training effectiveness in retail organizations. Future research emphasis and implications are then discussed that may help retailers better evaluate their sales training provisions while developing effective and accountable sales training efforts that will increase overall sales force productivity.
\end{abstract}

Keywords: Sales; Training; Evaluation; Sales Training Effectiveness

\section{INTRODUCTION}

ith two-thirds of the nation's Gross Domestic Product arising from retail consumption
(approximately $8 \%$ of our GDP comes from retailing) the retail industry is a significant sector of the
US economy (Farfan, 2011). In 2010, the total amount of sales generated from the retail industry was US $\$ 4.13$ trillion. There are approximately $1,122,703$ retail establishments with a total of 14.2 billion square feet of retail space while 6\% of our work force is employed as retail personnel (2011 U.S. Retail Industry Store Closings and Liquidations Roundup, 2011) with sales and customer service oriented responsibilities being their primary vocations.

With the economic downturn in the last 3 years, retailers have learned to place their retail personnel selling skills as an essential contributor to both business success and survival. They also know that business success is now defined by quality customer relationships and value-adding and that their sale force need significant amount of training in order that they can be highly consultative, customer-centric while adopting a "win-win" mentality (Global Survey of Sales Effectiveness, AchieveGlobal, 2011).

Ultimately, the goal of training is to make sales personnel successful in their jobs. Studies in various industries, including banking and healthcare, confirm the importance of sales training. This importance is necessary because, with an objective of improving sales force productivity, firms annually invest more than US\$30 billion dollars and 15 billion work hours to their training efforts (Attia, Honeycutt Jr., Attia, 2002). However, what is astounding is that while millions of dollars are spent on training sales workforce, the effectiveness of these training efforts is not often evaluated. $80 \%$ of companies do not measure their return on investment (ROI) on training, yet many managers have reported that their sales-training programs fail to make a lasting, visible impact on overall sales figures thereafter (AchieveGlobal, 2011).

What is the most effective and efficient means to develop a highly skilled sales force within an organization? How do organizations ensure that their training dollars are not wasted? How do sales managers make sure that they can continue to capitalize on their sales force strengths while improving weaknesses? How do 
organizations guarantee that they can continue to have a successful and productive sales force team? The answers to these questions will depend on a variety of variables and will differ from organization to organization depending upon the industry, selling cycle, method and content of training, and so on. However, today's sales managers must realize that to be able to answer these questions, the evaluation and assessment efforts of sales training must be carried out (Attia, Honeycutt Jr., and Leach, 2005).

As such, an important indicator of an effective sales training program in any retail organization is the evaluation of whether or not the training has directly impacted professional selling in terms of sales volume, sales personnel performance as well as other bottom line metrics. Without evaluating sales training effectiveness, retailers would not be able to make the necessary revision and renewal efforts to their sales training programs so that training can continuously be effective, accountable and significant to their organizations. Retail organizations could be spending considerable amount of time and resources conducting ineffective training programs continually perpetuating unimpressive sales force performances and contribution to their organizations.

\section{RESEARCH OBJECTIVES}

This paper extends the increasing body of research in the area of sales training evaluation. We hypothesize that retail organizations often fail to follow through in evaluating the effectiveness of their sales force training programs. This would mean there will be little or no corrective actions to improve or update their training programs, thereby marginalizing the effectiveness of sales training efforts as a whole.

This paper aims to investigate the importance of sales training evaluations placed by retail organizations and provides insights into the challenges and impediments faced by retailers in conducting training evaluation. In light of the importance of sales training and absence of systematic training evaluation, this article also proposes a model for evaluating sales training effectiveness. With our research findings, we hope to follow up with further indepth primary research in determining the scope and impact of sales training evaluation on the retail industry as a whole and propose a future research agenda in which a simplified, yet comprehensive, tool for measuring training effectiveness that is customized for retailers to make training evaluations easy and cost-effective.

\section{RESEARCH FINDINGS}

There has been an increasing trend toward accountability in organizations (Attia, Honeycutt Jr., and Leach, 2005); with every support function attempting to demonstrate its worth by assessing the value it adds to the organization (Geber, 1995). Phillips (1998) advocates capturing the return on investment (ROI) of training. This involves the systematic conversion of behavioral change and organizational results captured into dollar amounts, isolating the effects of training, then calculating and comparing to training costs (Honeycutt et al. 2001; Phillips 1998). To justify the expense of sales training, it must be cost-effective; that is, total benefits must exceed total costs. If a firm does not evaluate, then it is difficult to gauge the contribution made by the sales training program (Honeycutt E, 1996).

We found an overwhelming consensus amongst retail organizations that evaluation is indeed an essential and important training phase; however, it is often the most neglected. Between $35 \%$ and $76 \%$ of retailers evaluate only one level of sales training (Attia, Honeycutt Jr., Attia, 2002) while a majority do not measure training effectiveness against sales volume, sales personnel performance or other bottom line metrics. More significantly, up to $30 \%$ of corporations do not follow through and conduct formal or systematic training evaluation (Scovel $\mathrm{K}$, 1990).

According to retailers, conducting sales training evaluations necessitates additional time, money, and effort that many are unwilling or unable to spend when sales training is viewed as an expense. Twenty-two percent of respondents reported that a lack of adequate evaluation methodology constrained the evaluation of management training programs; while $42 \%$ of respondents reported that the most significant evaluation shortcoming was the lack of evaluation standards and metrics (Clegg W, 1987). Not surprisingly, the most common evaluation impediments reported are "time and money" (Honeycutt E, Stevenson T, 1989). 
Retailers also responded that a common evaluation restriction is the methodological process of collecting and using pertinent relevant data. Specific data problems encountered when evaluating training programs include lack of data, unreliable data, incomplete data, and untimely data. These anomalies restrict comparisons of sales figures and timely/accurate evaluation. A firm's information systems department must be tasked by upper management to supply the needed data in the correct form when required by sales managers and trainers (Attia, Honeycutt Jr., Attia, 2002). We surmise that with the lack of management support and emphasis, sales trainers would continue to have little or no urgency to conduct training evaluation.

\section{KIRKPATRICK'S FOUR-LEVEL TRAINING EVALUATION MODEL}

If retail organizations view sales training evaluation as necessitating additional time, money, and effort; a simplified, time-saving and in-expensive training evaluation tool must be developed to address this problem. This study essentially proposes utilizing Kirkpatrick's Four-Level Training Evaluation Model (Donald Kirkpatrick, 1994) to examine the interrelationships among its four levels of training evaluation (reaction, learning, behavior change, and organizational outcomes) and how it can be applied in determining sales training effectiveness.

For the past 40 years, the fundamental assessment and evaluation framework employed by sales training practitioners has been the 4-level model developed by Donald Kirkpatrick (Attia, Honeycutt Jr., and Leach, 2005). The model consists of four evaluation levels (i.e., reaction, learning, behavior, and results) arranged in ascending order of information provided by Kirkpatrick and of difficulty to accomplish (Honeycutt and Stevenson 1989). Using Kirkpatrick's evaluation framework, we believe the 4 evaluation levels could be incorporated into any retail sales training evaluation modules.

Kirkpatrick's Model has Four Levels of Evaluation:

Level 1 - Reactions: Measures how participants have reacted to training.

Level 2 - Learning: Measures what participants have learned from training.

Level 3 - Behavior: Measures whether what was learned is being applied on the job.

Level 4 - Results: Measures whether the application of training is achieving results.

Each successive level of evaluation builds upon the evaluations of the previous level, adding precision to the measure of effectiveness. This framework for training evaluation was widely used and has a reputation of being a logical, practical, and useful model (Bramley and Kitson 1994; Kaufman and Keller 1994). In Kirkpatrick's model, Level 1 (Reactions) measures how sales force has reacted to training, instructor, course, and learning environment. Every program should at least be evaluated at this level to answer questions regarding the trainees' perceptions and reactions towards training. More importantly, evaluation at this level gains knowledge if training is likely to be well received and relevant to their work. Negative reactions reduce the possibility of learning (Griego, Orlando V, 2004).

Level 2 (Learning) measures what sales force have learned from the training and it evaluates the extent sales trainees have advanced in knowledge, skills and/or attitudes. Instructors can affect three cognitive areas during training - they can teach new knowledge, skills, and attitudes. Therefore, when measuring learning, training evaluation would determine if one or more of the following has occurred: Was knowledge learned or gained? Were new skills or ways to improve existing skills gained? Were attitudes changed?

Level 3 - Behavior (Transfer) measures whether what was learned is being applied or transferred on the job. Level 3 focuses on the learner's ability to transfer the learning to where it is actually needed in the real world circumstances. Therefore, evaluators measure achievement of performance objectives in real-world settings.

Lastly, Level 4 (Results) measures whether the application of training is achieving quantifiable financial results. This evaluation measures the success of the training program in terms that executives and managers can understand such as increased sales, decreased costs, improved quality, and higher profits or training return on investment (Griego, Orlando V, 2004). 


\section{CONCLUSION}

Our research on retail organizations wanting to develop more strategically focused sales training efforts should agree that their training efforts must effectively change the behaviors and performance effectiveness of salespeople in ways that aid the sales force in meeting the strategic objectives of the firm. They must evaluate their sales training efforts in three broad areas. First, retailers must clarify their objectives and determine what training is most appropriate. Second, they must evaluate the impact of training on salespeople, focusing on the level of behavior change that results. Lastly, they must assess whether objectives were reached and if this was done cost effectively (Attia, Honeycutt Jr., and Leach, 2005).

From our investigation, it appears evident why many retail organizations would refrain from objectively evaluating their sales force training programs. Unless upper management understands the value of sales training evaluation, appropriate support and emphasis will be restricted. Even when training evaluation is conducted, minimal managerial expectations often fail to address time and budget restrictions as well as methodological problems. With retail managers failing to address these issues and concerns, improperly conducted evaluations result in a continuing lack of empirical evidence to support training revision and improvement. Without evaluation evidence, negative managerial perceptions or indifference toward sales training evaluation are only further reinforced. Thus, a vicious, self-permeating cycle propagates itself. Another way of looking at this dilemma is that current managerial perceptions about evaluation outcomes essentially determine how retailers undertake future sales training evaluation (Attia, Honeycutt Jr., Attia, 2002). Ultimately, trainers and training managers in retail organizations must seek to evaluate training programs, make improvements, and ensure more effective and accountable sales training efforts for their organizations.

\section{IMPLICATIONS}

Because sales training is a process, it is possible to efficiently design the process. However, to reach this goal, management must adopt the following normative actions: (1) Managers should not assume that all training is good, but should demand that objective sales training evaluations be conducted. That is, support for sales training evaluation must begin and emanate from the top of the firm. (2) Time and money restrictions are rationalizations or excuses for not evaluating training. Management must allocate funds for evaluation, and trainers and sales managers must devote the requisite time to evaluate their trainees. To insure that this happens, evaluation outcomes should become an integral part of the trainer's/manager's annual performance review and should impact their raise/promotion system. (3) Although myriad potential methodological problems exist, most can be reduced through proper planning. If managers understand what can go wrong, plans and changes to the evaluation process can be designed into the training process (Attia, Honeycutt Jr., Attia, 2002).

\section{FUTURE RESEARCH}

Our future research aims to examine the scope of sales force training evaluation with an objective of ascertaining its impact on retail organizations. Our findings will also help establish and accentuate the alignment of training interventions with the strategic focus of retail organizations. A secondary goal of this paper is to stimulate interest and further research in the application of Kirkpatrick's framework in retail sales training evaluation and assessment. If conducting sales training evaluations necessitates additional time, money, and effort that many retail organizations are unwilling or unable to spend, our future research agenda would then be to conduct a conceptual design study in devising and testing a template for simple and cost-effective sales training evaluation. A possibility would be in the form of a sales training scorecard that is suitable for retail organizations to use as a quick and inexpensive tool in measuring training effectiveness. Using the scorecard, retailers can evaluate sales training with minimum effort, identify training shortcomings, plan training interventions and make necessary continuous improvements. 


\section{AUTHOR INFORMATION}

Kim S. Tan is a Lecturer of Marketing at California State University San Bernardino (CSUSB). Kim has 23 years of industry work experience, with over 18 years in education involving teaching at college level and administrative work as a college academic vice dean. His industry-related experience includes client-related consultancy, project management, marketing research, and strategic organizational development having worked as a Marketing Research Consultant with Price Waterhouse before joining the education industry. Kim graduated from Louisiana State University with a B.Sc. in Business Administration with a concentration in marketing. In1984, he also earned an MBA with distinction from LSU. E-mail: ktan@csusb.edu.

Dr. Eric Newman is a professor and chair of the Department of Marketing in the College of Business and Public Administration at California State University San Bernardino. He received his Bachelor of Science and MBA from the University of Montana and a Ph.D. from Washington State University. Eric has worked for a number of companies such as Ask Mr Foster Travel, Center Ice Sports Consultants, Delta Airlines, Rio Tinto, and Zenith Computers. He continues to consult in a number of industries including the travel, tourism, sports, entertainment, hospitality, and real estate. E-mail: enewman@csusb.edu. Corresponding author.

\section{REFERENCES}

1. 2011 U.S. Retail Industry Store Closings and Liquidations Roundup - Complete and Ongoing List of Retail Chains Downsizing or Going Out of Business, (2011, Oct 19). Retrieved, Nov 8, 2011, from retailindustry.about.com

2. Farfan, Barbara, Retail Industry Information: Overview of Facts, Research, Data \& Trivia, 2011., about.com guide

3. Global Survey of Sales Effectiveness, AchieveGlobal, Inc. No. M01372 v. 1.0 (03/2011)

4. Ashraf M. Attia, Earl D. Honeycutt Jr., and Mark P. Leach, "A three-stage model for assessing and improving Sales force training and development", Journal of Personal Selling and Sales Management Issue: Volume 25, Number 3 / Summer 2005.

5. Geber, Beverly (1995), "Does Training Make a Difference? Prove It," Training, 32, 3 (March), 27-34.

6. Phillips, Jack J. (1991), Handbook of Training Evaluation and Measurement Methods, Houston: Gulf Publishing. (1998),

7. Honeycutt, Earl D., Jr., and Thomas H. Stevenson (1989), "Evaluating Sales Training Programs," Industrial Marketing Management, 18 (August), 215-222.

8. Griego, Orlando V.( 2004), Assessments and the Kirkpatrick Model, www.home.apu.edu

9. Kirkpatrick, Donald L. (1994), Evaluation Training Programs: The Four Levels, San Francisco: BerrettKoehler.

10. Bramley, P., and B. Kitson (1994), TQM for Training, New York: McGraw-Hill.

11. Honeycutt, Earl D., Jr., and Thomas H. Stevenson (1989), "Evaluating Sales Training Programs," Industrial Marketing Management, 18 (August), 215-222.

12. Ashraf M. Attia, Earl D. Honeycutt Jr., Magdy Mohamed Attia, The difficulties of evaluating sales training, Industrial Marketing Management, Volume 31, Issue 3, 15 April 2002, Pages 253-259

13. Honeycutt E. Conducting a sales training audit. Industrial Marketing Management 1996; 25(2):105 -13.

14. Scovel K. What's topping the charts in management training? Human Resource Executive 1990; 39 (April).

15. Honeycutt E, Stevenson T. Evaluating sales training programs. Industrial Marketing Management 1989; 18(3):215- 22.

16. Clegg W. Management training evaluation: an update. Train Dev J, 1987; 66- 8 (February). 
NOTES 